\title{
Socioeconomic Risk Factors for Cerebrovascular, Ischemic Heart and Hypertensive Mortality in Japan
}

\author{
Shunichi Araki, Katsuyuki Murata and Kazuhito \\ YoKOYAMA \\ Department of Public Health and Hygiene, Medical College \\ of Oita, Oita 879-56
}

\begin{abstract}
Araki, S., Murata, K. and Yokoyama, K. Socioeconomic Risk Factors for Cerebrovascular, Ischemic Heart and Hypertensive Mortality in Japan. Tohoku J. exp. Med., 1986, 149(4), 367-377 — The effects of a wide variety of socioeconomic factors on the mortality from cerebrovascular, ischemic heart and hypertensive diseases in 46 prefectures in Japan for the years 1970 and 1975 were analyzed by stepwise multiple regression analysis. The results indicated the following risk factors for the three major vascular causes of death in males and females in the two years: (1) rural residence for cerebrovascular disease (and employment and high income in females); (2) rural and urban residence for ischemic heart disease (in 1970 only); and (3) low income for hypertensive disease. The mortality from cerebrovascular disease within 46 prefectures was significantly higher in rural than urban areas in males and females in the two years, whereas the mortality from ischemic heart disease was higher in urban areas. The results were compared with recent data in Western countries. It is indicated that socioeconomic factors play important roles in the mortality from vascular causes of death as well as biological risk factors. - cerebrovascular disease ; ischemic heart disease ; hypertensive disease ; mortality; socioeconomic risk factors
\end{abstract}

Unique position of Japan has been recognized from the international viewpoint regarding mortality rates from cerebrovascular and ischemic heart diseases as well as malignant neoplasms. For example, Japan is among the nations highest for the mortality from cerebrovascular disease and among the lowest for ischemic heart disease (Friedman 1980). At a prefectural level, it has been shown that urban residence is the key factor affecting the mortality from various malignant neoplasms except leukemias (Araki 1986). It is thus indicated that there is a remarkable geographical difference in the the mortality from various causes of death. In this study, to clarify geographical factors affecting the mortality from major vascular causes of death, we analyze the effects of a wide variety of socioeconomic factors on the mortality from cerebrovascular, ischemic heart and hypertensive diseases by stepwise multiple regression analysis in the 46 prefectures in Japan. In addition, relative strength of effects of urban and rural Received May 30, 1986; accepted for publication June 17, 1986. 
residence is analyzed within the prefectures.

\section{Materials and Methods}

The following data were available in all but Okinawa prefectures (i.e., 46 prefectures) in Japan for 1970 and for 1975: (1) Age-adjusted mortality rates from cerebrovascular disease (ICD number, 430-438), ischemic heart disease (410-414) and hypertensive disease (400-404) in urban and rural areas; urban and rural areas were defined as all cities within a prefecture and all towns and villages outside cities, respectively (Japan Ministry of Health and Welfare 1974, 1978). (2) Twenty variables of socioeconomic factors (Japan Prime Minister's Office 1977). Stepwise regression analysis was conducted using Nippon Electric Corporation PC-9801 computer (Okuno et al. 1971).

As described in a previous report (Araki and Murata 1986), a total of 22 socioeconomic indicators (Table 1 and Fig. 1), including the 20 variables in this study, have been selected from the Japanese edition of the System of Statistical Indicators on Life (Japan Prime

TABLE 1. Twenty-two socioeconomic indicators in 46 prefectures for 1970 and 1975 classified by factor analysis

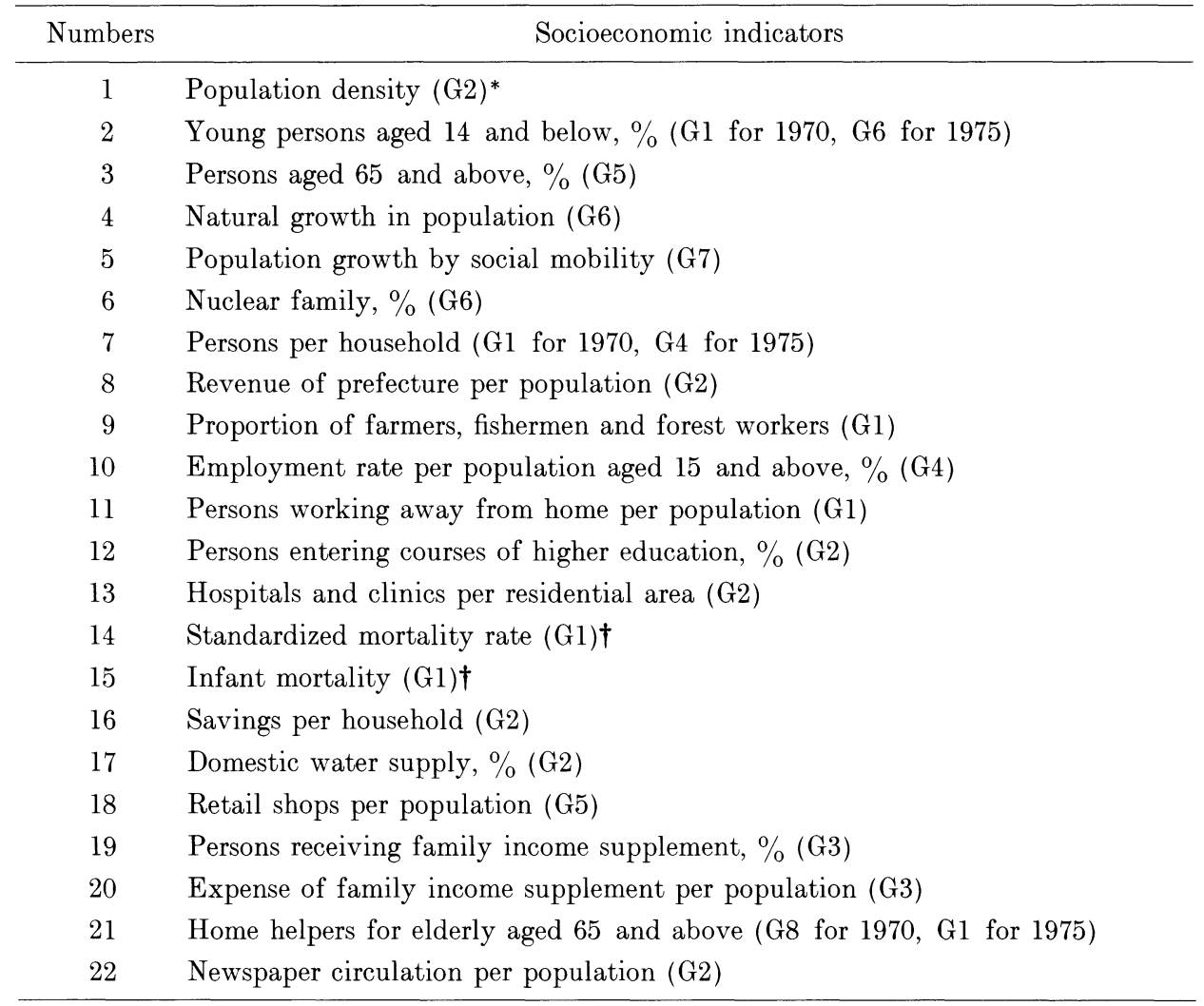

* Group numbers of factors are the results of a preceding study (Araki and Murata 1986) and are shown in parentheses.

$\dagger$ These two mortality indicators were not used for stepwise regression analysis in the present study as we intended to examine the effects of more specific indicators of rural residence on the mortality from cerebrovascular, ischemic heart and hypertensive diseases. 

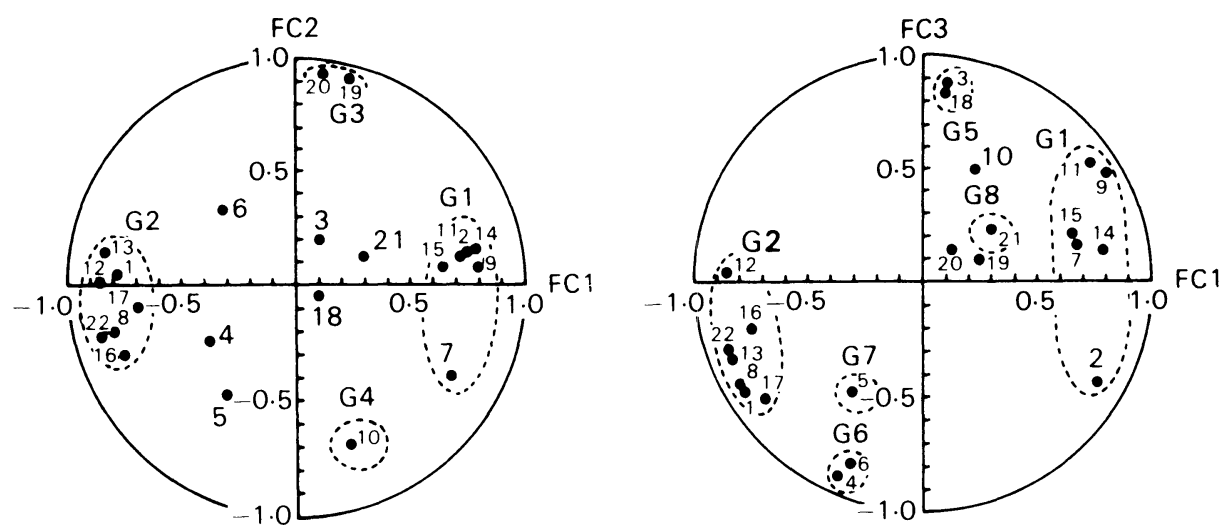

Fig. 1. Eight groups of factors classified from 22 socioeconomic indicators in 46 Japanese prefectures by factor analysis in 1970 (Araki and Murata 1986). FC1, 2 and $3=$ the first, second and third common-factors, respectively, extracted by factor analysis. The numbers of the indicators are as in Table 1. The indicators have been classified into eight groups (G1 to G8) according as the factor loadings were more than 0.5 or less than -0.5 on the basis of the four common-factors extracted: $\mathrm{G} 1=$ rural residence, $\mathrm{G} 2=$ urban residence, G3 $=$ low income, G4=employment and high income, G5=proportion of old population, G6 = proportion of young population, G7 $=$ social mobility, and G8 = social isolation of elderly. Eigen values were 11.5, 3.2, 2.6 and 0.9 for the first, second, third and fourth factors, respectively. Cumulative proportions were $0.52,0.67,0.79$ and 0.83 up to the first, second, third and fourth factors, respectively.

Minister's Office 1977), i.e. one to five indicators from each of the 13 major categories of social life with a total of 227 indicators; and then classified into eight groups of factors for the year 1970 and seven groups for 1975 by factor analysis. In the factor analysis, the first common-factor extracted in both 1970 and 1975 was rural or urban residence; the second was low income and unemployment; the third was prefectural age distribution; and, in 1970, the fourth was related to home help for the elderly and, in 1975, to social mobility.

TABLE 2. Eight groups of socioeconomic factors for 1970 and 1975 classified by factor analysis

\begin{tabular}{cl}
\hline Group numbers & \multicolumn{1}{c}{ Socioeconomic factors } \\
\hline G1 & Rural residence \\
G2 & Urban residence \\
G3 & Low income \\
G4 & Employment and high income \\
G5 & Proportion of old population \\
G6 & Proportion of young population \\
G7 & Social mobility (population growth by domestic migrants) \\
G8 & Social isolation of elderly* \\
\hline
\end{tabular}

* This factor belonged to rural residence (G1) factor in 1975 . 
The first group of socioeconomic indicators $(\mathrm{Gl})$ comprising proportion of farmers, fishermen and forest workers, which was classified on the basis of common-factors extracted by factor analysis, represents rural residence in both 1970 and 1975 (Table 2, Araki and Murata 1986). Similarly, the second group (G2), comprising population density, represents urban residence; the third (G3) is low income; the fourth (G4) is employment and high income; the fifth (G5) is proportion of old population; the sixth (G6) is proportion of young population; the seventh (G7) is social mobility (a difference between domestic migrants into and from a prefecture per population); and home help for the elderly (Indicator 21) is the eighth group (G8) in 1970, but moves into the first group (G1) in 1975. Rural residence (G1) factor is inversely related to urban residence (G2) factor; low income (G3) factor is inversely related to employment and high income (G4) factor; and proportion of old population (G5) factor is inversely to proportion of young population (G6) factor (Fig. 1).

\section{RESULTS}

The results of stepwise regression analysis are shown in Table 3. In both 1970 and 1975, the mortality rate from cerebrovascular disease for males was inversely related to urban residence (G2) factor (Indicator 12); the mortality for females was inversely related to urban residence (G2) and low income (G3) factors (Indicators 12 and 19). Similarly, the mortality from hypertensive disease for females was inversely related to employment and high income (G4) factor (Indicator 10) in 1970 and 1975 ; that for males was inversely related to employment and

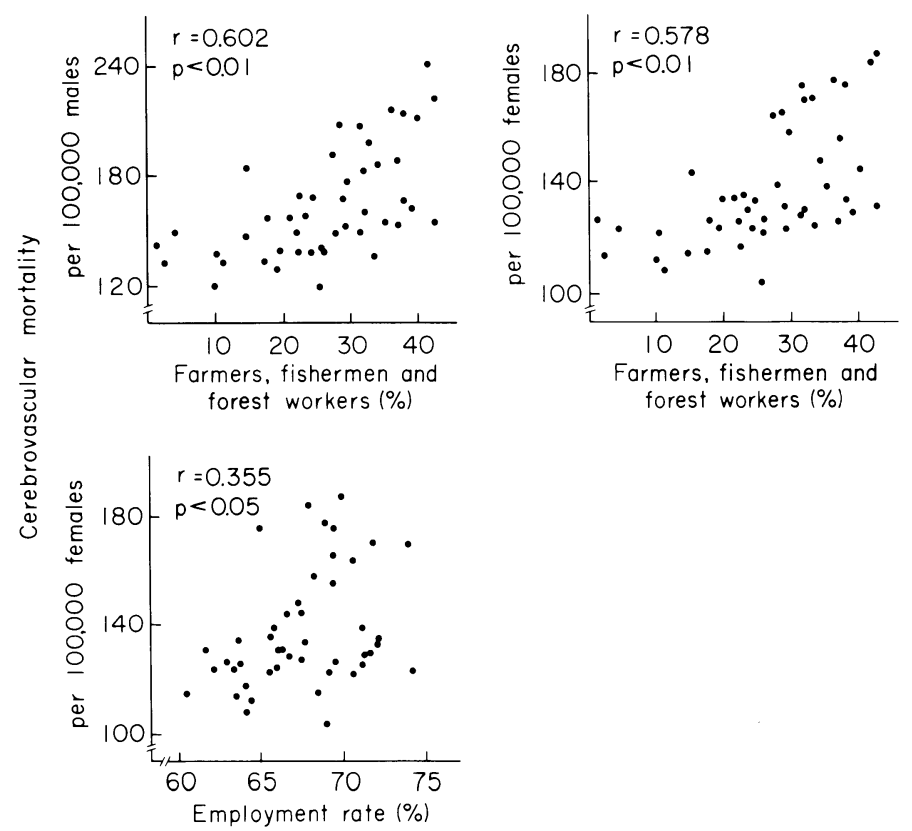

Fig. 2. Relationships between age-adjusted male and female mortality rates from cerebrovascular disease and socioeconomic factors in 46 prefectures in 1970. Farmers, fishermen and forest workers and employment rate represent rural residence and employment and high income factors, respectively. 

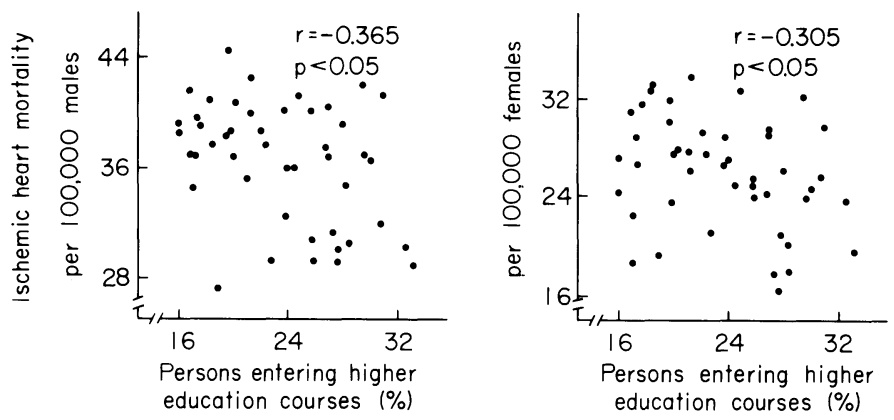

Fig. 3. Relationships between age-adjusted male and female mortality rates from ischemic heart disease and urban residence factor (persons entering higher education courses) in 46 prefectures in 1970.
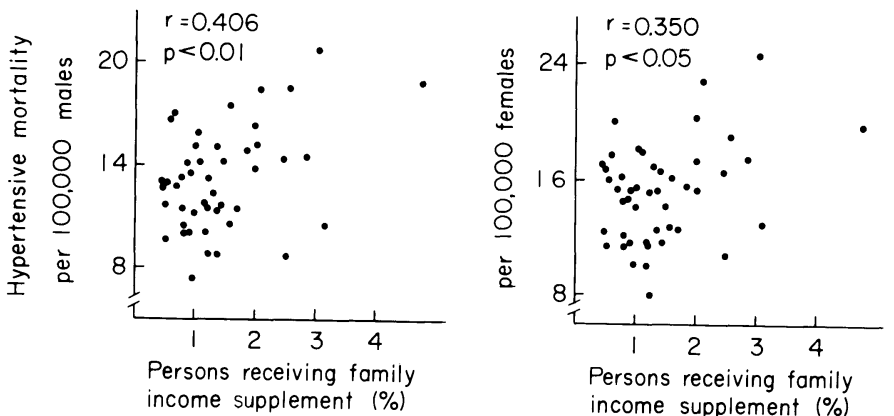

Fig. 4. Relationships between age-adjusted male and female mortality rates from hypertensive disease and low income factor (persons receiving family income supplement) in 46 prefectures in 1970.

high income (G4) factor (Indicator 10) in 1970 and was positively related to low income (G3) factor (Indicator 19) in 1975. In 1970, the mortality rate from ischemic heart disease for males was both inversely and positively related to urban residence (G2) factor (Indicators 8 and 12); the rate for females was inversely related to urban and rural residence (G1 and G2) factors (Indicators 11 and 12). Figs. 2-4 exemplify the effects of major socioeconomic factors on the mortality from cerebrovascular, ischemic heart and hypertensive diseases; Fig. 5 illustrates the mortality distribution in 46 prefectures. Mortality rates from all these diseases for males and females significantly decreased between 1970 and 1975 except ischemic heart disease for females (Table 4).

The difference in mortality rates from cerebrovascular, ischemic heart and hypertensive diseases between urban and rural areas within 46 prefectures is shown in Table 5. Cerebrovascular mortality was significantly higher in rural than urban areas for males and females in both 1970 and 1975, whereas the opposite was the case for ischemic heart mortality. No significant difference in hypertensive mortality between urban and rural areas was found in the two years. 
S. Araki et al.

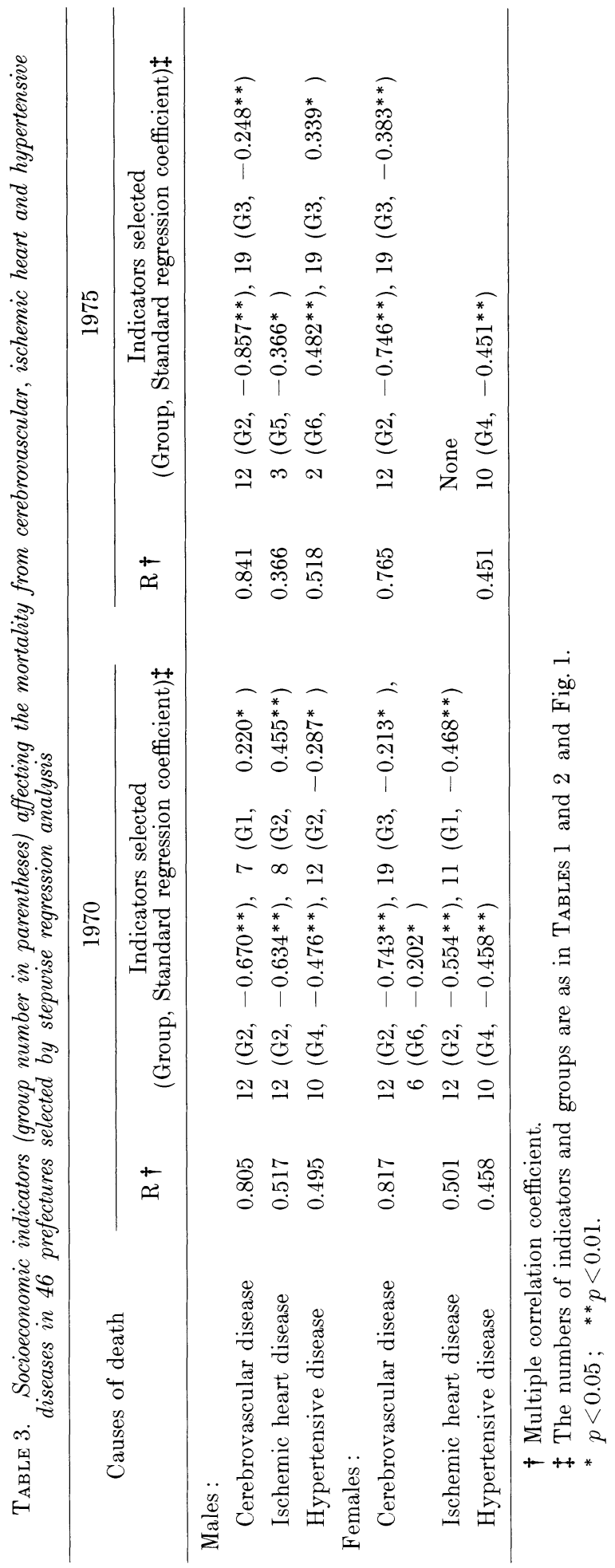


TABLE 4. Differences in age-adjusted mortality rates per 100,000 population from cerebrovascular, ischemic heart and hypertensive diseases in 46 prefectures between 1970 and 1975

\begin{tabular}{lcc}
\hline & \multicolumn{2}{c}{ Deaths, mean (SD) } \\
\cline { 2 - 3 } Causes of death & 1970 & 1975 \\
\hline Males : & $162.2(29.5)^{* *}$ & $124.4(19.7)^{* *}$ \\
Cerebrovascular disease & $36.4(4.4)^{* *}$ & $32.3(3.8)^{* *}$ \\
Ischemic heart disease & $13.0(3.0)^{* *}$ & $10.9(2.4)^{* *}$ \\
Hypertensive disease & & \\
Females : & $136.9(21.5)^{* *}$ & $111.1(15.3)^{* *}$ \\
Cerebrovascular disease & $25.8(4.5)$ & $25.1(3.7)$ \\
Ischemic heart disease & $15.0(3.4)^{* *}$ & $13.6(2.9)^{* *}$ \\
Hypertensive disease & & \\
\hline
\end{tabular}

** $p<0.01$ (paired-sample $t$-test).

TABLE 5. Differences in age-adjusted mortality rates per 100,000 population (mean with standard deviation in parentheses) from cerebrovascular, ischemic heart and hypertensive diseases between urban and rural areas within 46 prefectures

\begin{tabular}{|c|c|c|c|c|}
\hline \multirow{2}{*}{ Causes of death } & \multicolumn{2}{|c|}{1970} & \multicolumn{2}{|c|}{1975} \\
\hline & Urban areas $\ddagger$ & Rural areas $\S$ & Urban areas $\ddagger$ & Rural areas $\S$ \\
\hline \multicolumn{5}{|l|}{ Males: } \\
\hline $\begin{array}{l}\text { Cerebrovascular } \\
\text { disease }\end{array}$ & $158.5(26.8)^{* *}$ & $168.6(33.2)^{* *}$ & $122.4(18.7)^{* *}$ & $127.9(22.5)^{* *}$ \\
\hline $\begin{array}{l}\text { Ischemic heart } \\
\text { disease }\end{array}$ & $37.4(4.7)^{* *}$ & $35.2(6.1)^{* *}$ & $32.9(4.3)^{*}$ & $31.3(4.2)^{*}$ \\
\hline $\begin{array}{l}\text { Hypertensive } \\
\text { disease }\end{array}$ & $13.4(3.7)$ & $12.9(3.4)$ & $10.8(2.6)$ & $11.2(3.0)$ \\
\hline \multicolumn{5}{|l|}{ Females: } \\
\hline $\begin{array}{l}\text { Cerebrovascular } \\
\text { disease }\end{array}$ & $134.5(20.6)^{* *}$ & $142.0(23.8)^{* *}$ & $109.8(15.4)^{* *}$ & $113.4(16.4)^{* *}$ \\
\hline $\begin{array}{l}\text { Ischemic heart } \\
\text { disease }\end{array}$ & $26.4(4.8)^{* *}$ & $24.9(4.8)^{* *}$ & $25.7(3.9)^{* *}$ & $24.2(4.2)^{* *}$ \\
\hline $\begin{array}{l}\text { Hypertensive } \\
\text { disease }\end{array}$ & $15.1(3.8)$ & $14.7(4.2)$ & $13.8(3.2)$ & $13.3(3.2)$ \\
\hline
\end{tabular}

$\ddagger$ Cities; $\S$ Towns and villages outside cities.

* $p<0.05 ;{ }^{* *} p<0.01$ (paired-sample $t$-test).

\section{Discussion}

The results indicate that rural residence (G1) factor [a counterpart to urban residence $(\mathrm{G} 2)$ factor] positively affected the mortality from cerebrovascular disease at inter- and intra-prefectural levels for males and females in both 1970 
Males
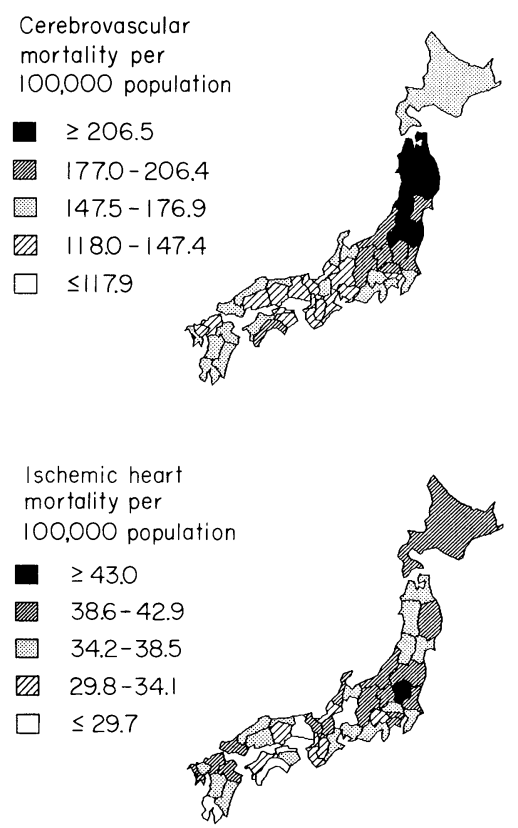

Hypertensive mortality per 100,000 population
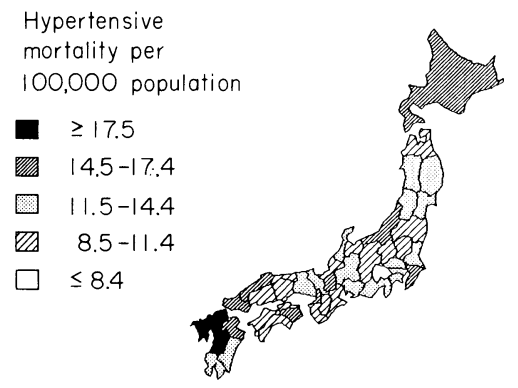

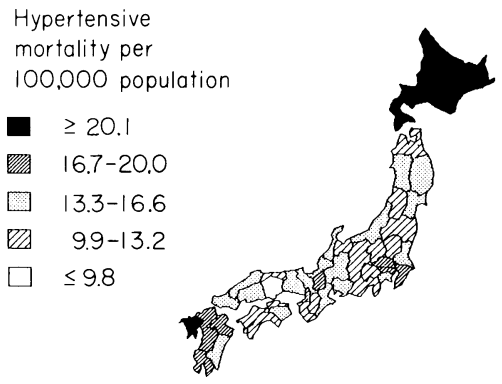

Fig. 5. Age-adjusted male and female mortality rates from cerebrovascular, ischemic heart and hypertensive diseases in 46 prefectures in Japan for 1970.

and 1975 (Fig. 2, Tables 3 and 5). These findings are in line with the well-known observation that the mortality from cerebrovascular disease is particularly high in the Tohoku region in Japan (Fig. 5) (Takahashi 1981; Tamashiro et al. 1981; Kagami 1983). It is thus indicated that rural residence is an essential risk factor for cerebrovascular mortality in Japan.

The mortality from cerebrovascular disease for females in 1970 and 1975 and for men in 1975 was also significantly related inversely to low income (G3) factor although these relations were statistically less powerful than the relation to urban residence factor (Table 3). Salt intake is known to be an important biological risk factor for cerebrovascular and hypertensive diseases (Dahl 1961; Sasaki 
1964 ; Friedman 1980; Kono et al. 1983). Therefore, the relations of salt use with both rural residence factor and employment and high income factor should be examined in further studies.

The effects of rural residence and employment and high income factors on cerebrovascular mortality in this study contrast with recent data in England and Wales. Namely, McKeown and Lowe (1974) reported that the mortality from vascular lesions of the central nervous system in 1970 had no relation to the size of towns and that the mortality for the years 1959-63 increased from the highest social class (Class I, SMR =86) to the lowest (Class V, SMR =135). On the other hand, twenty years previously, the trend was in the opposite direction in England and Wales; the mortality from cerebrovascular disease, together with ischemic heart and hypertensive mortality, was significantly higher in social class I and II than in IV and V (McKeown and Lowe 1974). A follow-up study, therefore, is needed in Japan regarding income effects on cerebrovascular mortality.

It appears that the mortality from hypertensive disease for males and females was positively affected by low income (G3) factor [a counterpart to employment and high income (G4) factor] in both 1970 and 1975 (Fig. 4 and Table 3). This finding is compatible with recent data in England and Wales, in which hypertension mortality for men aged 15-64 years in the years 1959-63 increased from social class I ( SMR $=85)$ to V $(\mathrm{SMR}=138)($ McKeown and Lowe 1974). Similar distinct social class gradients have been observed in the U.S.A. for hypertension and six other causes of death (Friedman 1980). Antihypertensive treatment has been shown to reduce overall mortality and cardiovascular morbidity in patients with moderate and severe hypertension in the U.S.A. (Joint National Committee 1980). Therefore, a difference in the intake of antihypertensive drugs among social classes should be examined in further studies.

The results of the mortality from ischemic heart disease in this study suggest that the mortality was affected by both rural and urban residence (G1 and G2) factors in males and females in 1970 with the former effects being greater at the inter-prefectural level (Table 3, Fig. 3). In contrast, the latter effects were significantly greater at the intra-prefectural level (Table 5). These findings suggest that ischemic heart mortality is especially high in urban areas in "rural" prefectures in Japan. Higher mortality from ischemic heart disease in urban areas within prefectures has been also reported in Poland (Rywik and Kups̄̄ $1985)$; further studies are needed to explain the similarity between the two countries. On the other hand, the absence of significant relations of ischemic heart mortality to income factors contrasts with recent data in England and Wales and in Finland, in which the mortality from ischemic heart disease tends to be higher in lower social class (McKeown and Lowe 1974; Heller et al. 1984; Notkola et al. 1985). Blood cholesterol, blood pressure and cigarette smoking are important biological risk factors for ischemic heart disease (Meredith Davies 1983 ; Shaper et al. 1985). Therefore, the relations of these factors with social class 
should be compared between Japan and Western countries in further studies.

Finally, geographical distribution of hypertension mortality apparently differed from those of cerebrovascular and ischemic heart mortality (Fig. 5), despite the fact that hypertension is an important risk factor for these diseases (Friedman 1980; Havlik and Feinleib 1982; Shaper et al. 1985). Similarly, the effects of socioeconomic factors on these three major vascular causes of death were not necessarily identical from each other (Tables 3 and 5). These findings indicate that socioeconomic factors play important roles in the mortality from cerebrovascular, ischemic heart and hypertensive diseases as well as biological risk factors.

\section{Acknowledgments}

We thank Miss S. Yasumi and Miss M. Sato for their assistance in preparation of this manuscript.

\section{References}

1) Araki, S. (1986) Social life factors affecting major malignant neoplasms in Japan. Tohoku J. exp. Med., 149, 221-228.

2) Araki, S. \& Murata, K. (1986) Social life factors affecting stillbirth, and infant and adult-disease mortality. Tohoku J. exp. Med., 149, 213-219.

3) Dahl, L.K. (1961) Possible role of chronic excess salt consumption in the pathogenesis of essential hypertension. Amer. J. Cardiol., 8, 571-575.

4) Friedman, G.D. (1980) Primer of Epidemiology. 2nd ed., McGraw-Hill, New York, pp. 58-88 \& 122-140.

5) Havlik, R.J. \& Feinleib, M. (1982) Epidemiology and genetics of hypertension. Hypertension, 4, Suppl. III, III • 121-III • 127.

6) Heller, R.F., Williams, H. \& Sittampalam, Y. (1984) Social class and ischaemic heart disease: Use of the male: Female ratio to identify possible occupational hazards. $J$. Epidem. Community Health, 38, 198-202.

7) Japan Ministry of Health and Welfare (1974) Special Report of Vital Statistics in 1970: Cause-Specific Age-Adjusted Mortality. Health and Welfare Statistics Association, Tokyo. (Japanese)

8) Japan Ministry of Health and Welfare (1978) Special Report of Vital Statistics in 1975: Cause-Specific Age-Adjusted Mortality. Health and Welfare Statistics Association, Tokyo. (Japanese)

9) Japan Prime Minister's Office (1977) System of Statistical Indicators on Life. Japan Statistical Association, Tokyo. (Japanese)

10) Joint National Committee (1980) The 1980 report of the Joint National Committee on detection, evaluation, and treatment of high blood pressure. Arch. intern. Med., 140, $1280-1285$.

11) Kagami, M. (1983) Regional variance of cerebrovascular mortality in Japan. Ecology of Disease, 2, 277-283.

12) Kono, S., Ikeda, M. \& Ogata, M. (1983) Salt and geographical mortality of gastric cancer and stroke in Japan. J. Epidem. Community Health, 37, 43-46.

13) McKeown, T. \& Lowe, C.R. (1974) An Introduction to Social Medicine. 2nd ed., Blackwell, Oxford, pp. 59-72.

14) Meredith Davies, J.B. (1983) Community Health, Preventive Medicine and Social Services. 5th ed., Bailliere Tindall, London, pp. 48-59.

15) Notkola, V., Punsar, S., Karvonen, M.J. \& Haapakoski, J. (1985) Socio-economic 
conditions in childhood and mortality and morbidity caused by coronary heart disease in adulthood in rural Finland. Soc. Sci. Med., 21, 517-523.

16) Okuno, T., Kume, H., Haga, T. \& Yoshizawa, T. (1971) Tahenryou Kaiseki Ho. Nikkagiren, Tokyo, pp. 25-157. (Japanese)

17) Rywik, S. \& Kups̄ē, W. (1985) Coronary heart disease mortality trends and related factors in Poland. Cardiology, 72, 81-87.

18) Sasaki, N. (1964) The relationship of salt intake to hypertension in the Japanese. Geriatrics, 19, 735-744.

19) Shaper, A.G., Pocock, S.J., Walker, M., Phillips, A.N., Whitehead, T.P. \& MacFarlane, P.W. (1985) Risk factors for ischaemic heart disease: The prospective phase of the British Regional Heart Study. J. Epidem. Community Health, 39, 197-209.

20) Takahashi, E. (1981) Geographic distribution of cerebrovascular disease and environmental factors in Japan. Soc. Sci. Med., 15D, 163-172.

21) Tamashiro, H., Enomoto, N., Minowa, M., Shibata, S., Ashizawa, M. \& Shigematsu, I. (1981) Geographical distributions of cerebrocardiovascular diseases in Japan : 19691974. Soc. Sci. Med., 15D, 173-186. 